\title{
LA SUPREMA CORTE DE ESTADOS UNIDOS ANTE EL FENÓMENO MIGRATORIO
}

\author{
MIGRATION AND THE US SUPREME COURT
}

\section{Mario MelgAR ADALID*}

RESUMEN: Los Estados Unidos se conformaron por la llegada de migrantes provenientes de todas partes del mundo. No obstante, el trato jurídico y humanitario que se ha brindado a los migrantes difiere según su origen. Son claros los ejemplos de discriminación a los chinos desde su arribo a ese país. Por otra parte, durante la Segunda Guerra Mundial se violaron derechos constitucionales de ciudadanos estadounidense de origen japonés, política que fue avalada por resoluciones de la Suprema Corte de Estados Unidos. El trato a los mexicanos no ha sido mejor. Las condiciones económicas de México han obligado a millones de trabajadores a abandonar sus tierras y hogares para intentar un mejor destino personal y familiar fuera de nuestro país. No obstante, dicha migración hacia los Estados Unidos tiene características distintas por su magnitud.

Palabras clave: Suprema Corte de Estados Unidos, interpretación constitucional, constitucionalidad de las normas, migración, federalismo judicial, precedentes judiciales, derechos humanos, discriminación racial, segregación.
ABSTRACT: The United States were formed by the arrival of migrants coming from different regions of the worlds. Notwithstanding, the legal and humanitarian treatment offered to migrants differs according to their originating region. The Chinese have evidently been discriminated. During the Second World War constitutional rights of U.S. citizens of japanese background were violated, a policy that at the moment was validated by the U.S. Supreme Cort. Mexicans have not been luckier in their quest to find better economic opportunities for themselves and their families by migrating from Mexico. In any case, migration from Mexico to the U.S. is phenomenon that is particular given the size and scope it represents.

Descriptors: Supreme Court of United States, Constitutional Interpretation, Constitutional Standards, Immigration, Judicial Federalism, Judicial Precedent, Human Rights, Racial Discrimination, Segregation.

${ }^{*}$ Investigador en el Instituto de Investigaciones Jurídicas de la UNAM. 


\section{INTRODUCCIÓN}

El fenómeno migratorio ha ocupado buena parte de la agenda bilateral de México y Estados Unidos. La frontera que separa a los dos países es la única en el mundo que divide un país altamente industrializado, de hecho la primera economía del mundo, con un país en vías de desarrollo. Los arreglos comerciales y los pactos de libre comercio entre los dos países, así como al acuerdo trilateral México-Estados Unidos-Canadá, el Tratado de Libre Comercio de América del Norte (TLCAN), han impulsado el intercambio de bienes, servicios y mercaderías entre los dos países, pero no se ha atendido el tránsito de personas y mucho menos se ha conformado un régimen de derechos humanos que ampare a las personas que participan en los intercambios. Se ha avanzado en la integración económica de la región, pero no se han resuelto los problemas sociales, económicos, y laborales.

México ha intentado un acuerdo migratorio integral con los Estados Unidos que sentaría las bases para que los trabajadores mexicanos que emigren participen en condiciones jurídica y socialmente aceptables en el mercado laboral estadounidense. Al mismo tiempo México ha intentado resolver la situación de millones de mexicanos que trabajan en Estados Unidos sin documentación migratoria. El gobierno federal de Estados Unidos, al menos en el discurso, ha expresado la necesidad de atender la cuestión migratoria. El presidente George W. Bush desde su campaña política en 2000 planteó que el problema migratorio y la inmigración ilegal es un asunto de la mayor seriedad. ${ }^{1}$ La economía de los Estados Unidos necesita a los trabajadores migrantes, que a su vez requieren oportunidades para sus necesidades personales y familiares, pero la inmigración provoca que las leyes de los Estados Unidos no se cumplan y haya violaciones a los derechos humanos.

Por aquellos días el presidente mexicano Vicente Fox, recién inaugurado, se convirtió, al decir de Bush, en su primer socio en materia migratoria. ${ }^{2}$ El 5 de septiembre de 2001 el presidente mexicano fue el primer huésped que recibió Bush en una cena oficial. Ambos discutieron, dice

En México no se utiliza el término ilegal para identificar a los migrantes sin documentos. Con razón se ha acuñado en su lugar el término indocumentado. No obstante a lo largo del texto utilizaré el término ilegal si es en referencia a la expresión que hacen los estadounidenses.

2 Bush, W. George, “Decisions Points”, Crown Publishers, Nueva York, 2010, p. 302. 
Bush, la posibilidad de un programa temporal de trabajadores que permitiera a los mexicanos entrar a los Estados Unidos de manera legal y trabajar durante un tiempo específico. Fox estuvo de acuerdo pero planteó además la legalización de los mexicanos que vivían en los Estados Unidos. Un programa que se denominó regularización. Bush escribe en sus memorias que dejó claro que eso nunca pasaría. En México nos hicieron creer que habría un acuerdo integral coloquialmente conocido como la "Enchilada Completa". Bush señala que eso no pasaría porque se trataría en el fondo de una amnistía que convertiría a los migrantes "ilegales" automáticamente en ciudadanos, rompería con el Estado de derecho y estimularía futuras migraciones ilegales. ${ }^{3}$

Durante su campaña presidencial Barack Obama planteó atender el asunto migratorio con la oferta de una ley integral. La difícil agenda económica y los problemas internacionales impidieron avanzar en esta propuesta de campaña política. Mientras tanto algunos estados de la Unión Americana decidieron atender directamente el problema migratorio. La explicación de algunos estados para actuar de esta manera fue, que ante la inactividad del gobierno federal en asegurar las fronteras, resultaba necesario aplicar estrictamente las leyes migratorias, y que correspondería a los estados colaborar en la materia.

El estado de Arizona decidió legislar sobre migración, materia reservada a la esfera federal. Otros estados han expresado su intención de expedir leyes similares que limiten, controlen y hasta eviten la migración de trabajadores indocumentados. En este sentido las legislaturas de Oklahoma, Carolina del Sur, Idaho, Utah, Missouri, Texas, Carolina del Sur Maryland, Minnesota y Colorado han mostrado interés en legislar sobre la materia migratoria.

La Ley de Arizona SB 1070 se expidió contra la opinión de un segmento importante de la sociedad estadounidense y concretamente del gobierno federal. El propio presidente Obama declaró públicamente su oposición y ordenó la impugnación de la ley ante un tribunal federal.

Este artículo presenta un panorama de las definiciones jurídicas sobre el tema migratorio. En forma particular se describe el marco histórico jurídico a la ley expedida por la Legislatura del Estado de Arizona. La constitucionalidad de su contenido será resuelto por instancias judiciales federales y es altamente probable que cualquiera que sea el resultado de 
la decisión judicial en la esfera federal, será la Suprema Corte la que resuelva en definitiva.

Para la preparación de este artículo se utilizaron diversas fuentes y particularmente los textos de algunas resoluciones emblemáticas de la Suprema Corte que explican el sentido de las determinaciones. De igual manera se aprovechó el contenido de textos producidos por especialistas en historia del derecho constitucional estadounidense y particularmente en historia de la Suprema Corte de Estados Unidos. Llama la atención los textos producidos por jueces asociados de la Suprema Corte que mantienen la tradición de publicar sus puntos de vista sobre el papel que juega ese alto órgano judicial en la conformación de políticas y en el juego político y democrático. De igual manera se utilizaron textos de prensa que dan cuenta sobre la actividad de la Suprema Corte. La explicación comprende algunos episodios en los que la Suprema Corte emitió la última palabra al resolver asuntos que, como será probablemente el de la Ley de Arizona SB 1070, han ocupado la atención de la opinión pública de los Estados Unidos y como ha sido en este caso la opinión pública y académica de México. Hubo interés especial en mostrar con algún detalle lo que sucedió con ciudadanos estadounidenses descendientes de japoneses durante la Segunda Guerra Mundial. Las resoluciones de la Suprema Corte que se aplicaron en esos casos son una muestra de cómo el derecho y el objeto que pretende tutelar - los derechos humanos - pueden quedar subordinados al interés político de momento.

\section{ESTADOS UNIDOS: TIERRA DE MIGRANTES}

Estados Unidos está conformado por migrantes que llegaron a ese país a lo largo de múltiples oleadas. De 1815 hasta el inicio de la Guerra de Secesión arribaron cinco millones de migrantes provenientes la mitad de Inglaterra, el cuarenta por ciento de Irlanda y el resto de Europa continental. Entre el final de la Guerra Civil y 1890 llegaron otros diez millones procedentes del noroeste de Europa, Inglaterra, Gales, Irlanda, Alemania y Escandinavia. Después, al terminar el siglo, antes de la I Guerra Mundial, quince millones más en su mayoría del este y sur de Europa: polacos, judíos, rusos, ucranianos, eslovacos, croatas, eslovenos, húngaros, griegos, rumanos e italianos. 
La libertad de tránsito era absoluta hasta que los estadounidenses se percataron que la llegada indiscriminada de migrantes generaba sobrepoblación y consecuentemente pérdida de oportunidades de trabajo para los nacionales. Se produjeron entonces leyes restrictivas de la migración. Se negó la entrada a personas con perturbaciones mentales, a los criminales, a los indigentes, a las prostitutas y particularmente a los chinos. Entre 1866 y 1915 la riqueza y extensión del país permitió brindar a los migrantes extranjeros las condiciones para vivir mejor que en su lugar de origen: estado de derecho, educación, tierras, vivienda, empleo, ropa y alimentos.

Migrantes provenientes de todas las regiones del mundo conformaron un "Melting Pot", metáfora que explica la mezcla conformada por diferentes grupos que entre sí integran una sociedad distinta con características diferentes a las de cada uno de sus integrantes. El resultado del Melting Pot es la cultura americana, concepto opuesto al multiculturalismo, tendencia que pretende que las distintas expresiones culturales, sociales y hasta raciales deben conservar sus características originales y así dar una mayor riqueza al grupo social al que se integran. El movimiento migratorio ha sido incesante y ha dado como resultado una sociedad pluricultural y pluriétnica. El discurso oficial es de una sociedad abierta que recibe todas las razas y orígenes para incorporarlos a una gran nación en donde el mensaje es que la democracia y justicia brillan para todos. ${ }^{4}$

\section{PRIMERO, LA DISCRIMINACIÓN A LOS CHINOS}

No obstante la retórica, los ejemplos de discriminación a los extranjeros son proverbiales. La persecución de chinos en California y las barreras para impedir su incorporación al sistema son el mejor ejemplo del trato desigual a ciertos extranjeros. Se estima que en la segunda mitad del siglo XIX, había 75 mil chinos en California. En los debates de la Constitución de California se dijeron cosas como estas: "los chinos no están preparados para asimilarse a nuestra raza", o algo como "mezclarse con ellos produciría un híbrido despreciable". Se llegó a proponer una ley que

4 Una explicación sobre las distintas fases del fenómeno migratorio en los Estados Unidos se encuentra en Johnson, Paul, A History of the American People, Nueva York, Harper Perennial, 1999, cfr. pp. 283-284, 288-90, 386-87, 513-14, 661-62, 669-70, 941, 956. 
prohibiera a los particulares o a las entidades públicas contratar chinos para cualquier trabajo. Se promulgó una ley que negaba a los barrios chinos la protección policíaca. ${ }^{5}$ Conforme se dieron violaciones a derechos fundamentales, los tribunales federales tomaron cartas en los asuntos y la Suprema Corte determinó revisar algunas causas.

Es conocido el caso de Yick Wo vs. Hopkins (1866), que llegó a la atención de la Suprema Corte. Yick Wo solicitó un permiso para operar una lavandería en un edificio de madera. Para entonces, una ordenanza de la ciudad de San Francisco había prohibido que las lavanderías funcionaran en edificaciones de madera, como operaban todas las lavanderías chinas de esa época. La medida obligó a los chinos a cerrar sus negocios y consecuentemente el negocio de las lavanderías quedó en manos caucásicas. La solicitud le fue negada. No obstante la negativa, seguramente con el propósito de iniciar un litigio, Yick Wo siguió con la operación de su negocio. Fue arrestado y multado. Las sanciones eran considerables: multa de mil dólares y prisión hasta por seis meses. El asunto llegó a la Suprema Corte la que anuló la sanción a Yick Wo. La Corte resolvió que la manera en que se aplicó la reglamentación resultaba violatoria de la garantía de protección igualitaria de las leyes y violatoria de la decimocuarta enmienda. ${ }^{6}$ Otros casos tuvieron menos suerte y la Suprema Corte llegó a confirmar como constitucionales actos de autoridad violatorios de derechos fundamentales de los chinos en Estados Unidos.

\section{LOS JAPONESES-AMERICANOS EN LOS CAMPOS DE CONCENTRACIÓN}

Con motivo de la conflagración mundial de los años cuarenta, la Suprema Corte decidió algunos casos de ciudadanos estadounidenses de origen japonés a quienes el gobierno federal violó derechos fundamentales anteponiendo razones de orden público que han ocupado la atención de estudiosos del derecho estadounidense y de las decisiones de la Suprema Corte. La evacuación masiva de los descendientes de japoneses que vivían en el estado de California y en los estados de la Costa Oeste, con motivo de la conflagración de los Estados Unidos con Japón derivada de

5 Friedman, Lawrence M., A History of American Law, Nueva York, Simon \& Schuster, 2007, p. 263.

6 Hall L, Kermitt, The Oxford Companion to the Supreme Court of the United States, Oxford, Oxford University Press, 2005, pp. 1109 y 1110. 
los ataques de Pearl Harbor en 1941 que avaló la Suprema Corte es un oprobio del sistema político estadounidense. Durante la gestión del presidente Franklin D. Roosevelt, (1933-1945) el reconocido campeón de la democracia americana, se determinó la concentración forzosa, durante tres años, de japoneses-americanos que residían en la Costa Oeste de los Estados Unidos. No obstante ser ciudadanos estadounidenses se les trató como si fueran prisioneros de guerra, los situaron en barracas protegidas por alambre de púas y resguardados por soldados armados.

La inmigración de japoneses a los Estados Unidos ocurrió en las primeras décadas del siglo XX. Para fines del siglo anterior (1890), se estima que había únicamente dos mil japoneses en la Costa Oeste. ${ }^{7} \mathrm{Al}$ crecer la ola japonesa y llegar a la cifra a 100,000 migrantes en la Costa Oeste, el Congreso de los Estados Unidos determinó detener la migración japonesa. Se les negó la ciudadanía y se les excluyó del derecho de poseer o renta tierras. Conforme a su indomable carácter y laboriosidad, encontraron vías para seguir progresando desde el punto de vista económico. Le dieron la vuelta a la Ley de Tierras para Extranjeros (Alien Land Law), e iniciaron el cultivo en tierras agrícolas propiedad de terceras personas, o bien en terrenos a nombre de sus hijos, amparados en la decimocuarta enmienda, pues los hijos ya eran ciudadanos estadounidenses al haber nacido en los Estados Unidos. El trabajo y organización de la comunidad japonesa de California los llevó a generar la mitad de la producción de vegetales en el Estado, hasta que llegó el ataque a Pearl Harbor y con ello el pánico generalizado a cualquier imagen relacionada con Japón. En muchas ocasiones la psicosis fue motivada por intereses económicos. Peter Irons refiere que los líderes de la Grower Shiper Vegetable Association, poderosa organización integrada por blancos, se aprovecharon del pánico de Pearl Harbor para acabar con sus competidores. " "Se nos acusa de querer deshacernos de los japoneses por razones egoístas, para ser honestos la verdad es que sí es cierto". ${ }^{9}$

E1 temor de que los japoneses asentados en la Costa Oeste hubieran participado de alguna manera en favorecer el ataque generó preocupa-

7 Irons, Peter, “A People's History of the Supreme Court", Nueva York, Penguin Books, 2006, p. 349.

8 Peter Irons trata con detalle este caso en Justice at War: The Story of JapanesseAmerican Internment Cases (1983).

$9 \quad$ Ibidem, p.350. 
ción ampliamente propagada. Leland Ford, un congresista de Los Ángeles, demandó con urgencia que todos los japoneses, fueran o no ciudadanos, deberían ubicarse en campos de concentración, lejos de la costa del Océano Pacífico. Walter Lippmann, uno de los intelectuales liberales más reconocidos de la época se dolió de la falta de decisión del gobierno de Washington de adoptar una política de evacuación e internamiento masiva. ${ }^{10} \mathrm{El}$ incidente estuvo además rodeado de contenido racial. El abogado general de los Estados Unidos, Francis Biddle, pidió asesoría a tres jóvenes abogados egresados de la prestigiada escuela de leyes de Harvard. Los tres juristas estimaron que como es muy difícil para el ojo occidental distinguir a un japonés de otro, había que recurrir al confinamiento de todos para evitar que hubiera espías. No sucedería lo mismo con los italianos y alemanes - contra quienes los Estados Unidos también entraron en guerra- pues sus características raciales no diferían mayormente de la mayoría de los estadounidenses

Los oficiales del Ejército a cargo del confinamiento de los japoneses llegaron a extremos e injusticias. Así sucedió con el del General De Witt que mandó una recomendación final al Secretario Henry L. Stimson, con la que señalaba que si bien no había evidencia de que los japoneses que habitaban la costa Oeste de los Estados Unidos hubieran participado en actos de sabotaje, eso no era indicativo que no participarían en el futuro. "La raza japonesa es una raza enemiga". Si bien es cierto que hay segunda y tercera generación de japoneses nacidos en los Estados Unidos eso no diluye sus lazos raciales, señaló. A él se le atribuye la famosa frase: "A Jap's a Jap".

Con este escenario se presentaron ante las cortes federales tres casos que se volverían emblemáticos. Gordon Hirabayashi, Min Yasui y Fred Korematsu. Los tres ciudadanos estadounidenses de origen japonés no acataron las órdenes del General de Witt y los tres casos llegaron a la Suprema Corte. Gordon Hirabayashi pertenecía, igual que sus padres, a la secta religiosa de los cuáqueros. Cuando se impuso el toque de queda a los japoneses, Gordon Hirabayashi estudiaba en la Universidad y vivía en las instalaciones de la YMCA. Obedecía el toque de queda y para ello tenía que correr todos los días del campus universitario al dormitorio. Después de hacerlo durante un mes, decidió que era absurdo que él,

10 Lippman fue un periodista crítico y filósofo que trató de reconciliar las tensiones entre la libertad y la democracia como lo plantea en su libro Liberty and the News, 1920. 
también un ciudadano estadounidense, como los demás estudiantes que vivían en el dormitorio de la YMCA, tuviera que salir corriendo todas las tardes. Se habían emitido ya las órdenes para que los descendientes de japoneses independientemente de su nacionalidad deberían deshacerse de sus propiedades y reportarse en los centros de reunión. Mientras llegaban las órdenes, Gordon Hirabayashi hacía trabajo social en su centro cuáquero, en favor de varias familias que llevaban sus pertenencias y preparaban su equipaje para acudir a los centros de reunión, de donde serían trasladados a los campos de concentración, generalmente hipódromos en que las caballerizas sirvieron como las celdas de los americano/ japoneses concentrados. Al llegar las órdenes de acudir a los centros de confinamiento, Min se negó. Acudió a la oficina del FBI y manifestó que no iría a Puyallup, el centro al que había sido asignado. El argumento que utilizó Gordon Hirabayashi se basaba en la doctrina cuáquera. Su declaración señaló que el principio de la sociedad religiosa a la que pertenecía le había enseñado que no podía conciliar el designio de Dios, parte del cual estaba contenido en la Carta de Derechos y en la Constitución de los Estados Unidos, con la orden discriminatoria en contra de japoneses extranjeros y ciudadanos estadounidenses de origen japonés. El FBI lo arrestó por violar el toque de queda y las órdenes de evacuación. Gordon Hirabayashi fue puesto en prisión a la espera de un juicio.

Min Yasui nació en el estado y fue estudiante de la Universidad de Oregon. Se ofreció como voluntario para el programa de entrenamiento de oficiales de la reserva del Ejército. Después de recibir una comisión como sargento segundo, Min Yasui ingresó a la Escuela de Leyes de la Universidad y se graduó como abogado en 1939. Imposibilitado para encontrar un trabajo como jurista, consiguió uno en el consulado japonés en Chicago. Su función era básicamente burocrática pero eventualmente lo comisionaban para hacer presentaciones públicas sobre la política japonesa en Asia. Lo hizo ante el Club Rotario y otras organizaciones similares. Como ciudadano estadounidense no se registró ante el Departamento de Estado como agente extranjero. Al día siguiente del ataque en Pearl Harbor recibió un telegrama de su padre con el que lo conminaba a enlistarse inmediatamente en el Ejército de los Estados Unidos, lo que sucedió a la mayoría de los jóvenes estadounidenses. ${ }^{11}$ Dejó su trabajo en el consulado japonés. Min recibió la orden de reportarse al Fuerte Vancouver 
cerca de Portland en el Estado de Oregon. Cuando se presentó uniformado no le permitieron el acceso y le indicaron que saliera de la base militar. Posteriormente Min intentó ingresar al Fuerte en ocho ocasiones y siempre fue rechazado en base a sus características raciales. Existía un toque de queda aplicable a los extranjeros que Min trató de desafiar. En marzo de 1942, ya con la paranoia generalizada del ataque japonés a Pearl Harbor, Min se acercó con un policía del centro de Portland y le pidió que lo arrestara por tratarse de una persona de origen japonés que había violado el toque de queda. El policía le indicó que corriera a su casa y evitara problemas. Min no atendió la sugerencia insistió en que debería ser arrestado, lo que sucedió finalmente. Pasó nueve meses encarcelado en solitario antes de que iniciara su juicio.

Fred Korematsu, otro de los japoneses cuyo caso llegó también a la Suprema Corte, no se opuso al confinamiento por razones religiosas o por cuestiones militares. El no propició su detención como lo hicieron Min Yasui y Gordon Hirabayashi. Por el contrario, Fred trató de cambiar su fisonomía para no parecer japonés. Se hizo una cirugía plástica para que le abrieran los parpados y modificaran su nariz para "occidentalizarla". Una tarde en San Leandro California paseaba por una de las calles acompañado de su novia. A pesar de identificarse como otra persona y de llevar una credencial falsa, Fred fue descubierto y llevado a las oficinas de la policía. Fred Korematsu había nacido en California, había concluido su educación secundaria y tuvo que dejar la Universidad por razones financieras. Entró a una escuela técnica de soldadura y a ese oficio se dedicaba hasta el ataque a Pearl Harbor en que el sindicato de soldadores expulsó a los japoneses. Fred decidió cambiar su apariencia infructuosamente y como tampoco aceptó las ordenes de evacuación para ser confinado en los campos de concentración fue arrestado. Aceptó el auxilio legal de la American Civil Liberties Union, a través de su Director en San Francisco. Compartió con Gordon Hirabayashi y Min Yasui las mismas razones para defender sus derechos constitucionales.

\section{LOS JUICIOS DE LOS JAPONESES-AMERICANOS}

Los juicios en las cortes federales fueron uniformes y muy superficiales. El juez federal Lloyd Black, con sede en Seattle, rechazó la argumentación de los abogados de Gordon Hirabayashi de que las órdenes giradas por el General De Witt violaban la Cláusula del debido Proceso 
y la quinta enmienda al afectar a un solo grupo social con "restricciones especiales" que no se impusieron a otros grupos. El argumento del juez Black pareciera más el de un estratega militar. En su resolución señaló, al referirse a la proximidad de la ciudad de Seattle a las fábricas de aviones militares y a las bases navales que saboteadores, paracaidistas y soldados japoneses pudieran hacer uso de las tácticas de infiltración. Black dirigió — como lo señala Peter Irons — a los jurados para que sentenciaran a Gordon Hirabayashi en menos de diez minutos de deliberaciones. ${ }^{12}$

Min Yasui fue también encontrado culpable y si bien su juicio tardó más que el de Gordon, el resultado fue el mismo al declararlo culpable. Min jamás había estado en Japón y fue cuestionado sobre la religión sintoísta, práctica oficial en ese país. Al preguntársele si era adepto a la misma, Min declaró que tanto su padre como su madre eran metodistas y verdaderos cristianos. El juez de la causa Alger Fee, no utilizó al jurado y el declaró culpable a Min por violar el toque de queda. Fee dejó constancia en la sentencia de que Min era ciudadano japonés y sujeto al Emperador de Japón, ello no obstante tener constancia de la ciudadanía estadounidense del acusado. Vinculó inexplicablemente a Min con los ataques a Pearl Harbor y le impuso una multa exorbitante de 5,000 dólares, una enorme cantidad para la época y para las condiciones económicas y sociales de Min, además de un año de cárcel.

Fred Korematsu compareció a juicio ante el juez Adolphus St. Sure quien al contrario de sus colegas judiciales trató a Korematsu con respeto y consideración. Independientemente de los buenos modales del juez y de lo divertido que resultó que en su declaración, (Korematsu explicó que había tratado de cambiar sus rasgos, pero que evidentemente no lo había logrado, pues seguía pareciendo un japonés), fue condenado a cinco años de libertad condicionada. El juez al suponer que apelarían la sentencia fijó una fianza de 2,500 dólares. Al salir del juzgado con su libertad bajo fianza fue detenido por un policía que con una pistola apuntándole que lo trasladó a una prisión militar. De ahí fue llevado al hipódromo de Tanforan, en donde sus padres estaban detenidos. Habitaron en unas caballerizas, en espera de ser transferidos al campo de concentración en el Desierto de Utah.

Los tres casos llegaron a la Suprema Corte después de que los jueces de circuito confirmaron las resoluciones. Salvo el caso de Fred Koremat-

12 Irons, Peter, op. cit., p. 354. 
$\mathrm{su}$, en el que los jueces asociados pidieron al amable juez St. Sure que aclarara su sentencia. La Corte atendió las causas de Gordon Hirabayashi y Min Yasui. No se presentó ninguna prueba del peligro que significaban los acusados respecto al espionaje y sabotaje a las instalaciones militares de la Costa Oeste. Los argumentos del gobierno se sustentaron en que un número importante de japoneses carecía de un sentimiento de lealtad hacia los Estados Unidos. La discriminación legal de que fueron objeto, como las ya referidas acciones para privarlos de su ciudadanía o de la propiedad de sus tierras de cultivo, han generado en ellos, argumentó el gobierno, una consecuente liga con Japón y un sentimiento compensatorio de orgullo racial. Esto hace muy difícil diferenciar a quienes son leales de quienes no lo son.

El solicitor general de los Estados Unidos, funcionario designado para representar al gobierno de los Estados Unidos ante la Suprema Corte, insistió en los argumentos de que los japoneses no se asimilarían nunca a la cultura y tradiciones de los Estados Unidos. Existe, mencionó ante la Corte, temor fundado de que ayudarán al enemigo. Harold Evans el abogado de Hirabayashi, se basó en lo resuelto por la Corte en 1866, en la causa Milligan derivada de la Guerra de Secesión. ${ }^{13}$ Indicó que la autoridad legislativa sobre civiles no debe delegarse a la autoridad militar, cuando el área en cuestión no sea estrictamente un área militar. La consecuencia de aquella causa que favoreció a los simpatizantes de la Confederación es que los tribunales militares no deben juzgar a los civiles, si es que hay tribunales ordinarios disponibles. El juez Felix Frankfurter que había sido procurador militar en la Primera Guerra Mundial, le dijo que nada tenía que ver aquel caso de contenido fundamentalmente político con las condiciones en 1943. Dice Irons que ni siquiera contestó una pregunta al responderle que eso sería algo que la Corte tendría que decidir. ${ }^{14}$

La Suprema Corte resolvió la causa de Hirabayashi y emitió una breve opinión en la de Yasui. La decisión fue propuesta por el Chief Justice Harman Fiske Stone y se resolvió en forme unánime. La razón es que Gordon Hirabayashi había violado la disposición del toque de queda que lo obligaba a estar en su casa antes de las $8 \mathrm{pm}$. La resolución se basó en cuestiones de clasificación de raza de los ciudadanos, debido a las extraordinarias circunstancias que vivía el país. La resolución señala que

13 Ex parte Milligan 71 US2 (1866).

14 Irons, Peter, op. cit., p. 356. 
cualquiera que sean los puntos de vista que se tengan sobre la lealtad de los ciudadanos de origen japonés a los Estados Unidos no se puede considerar como infundado los juicios del Congreso o de las autoridades militares de que hay integrantes de esa comunidad americano-japonesa que son desleales a los Estados Unidos, cuyo número y fortaleza no puede determinarse de manera precisa y pronta. ${ }^{15}$ La decisión unánime tuvo tres votos concurrentes cercanos a la disidencia. Los juecesWilliam O' Douglas, Frank Murphy y Wiley Rutledge señalaron que las distinciones que se sustentan en el color y el origen son completamente inconsistentes con sus tradiciones e ideales. Votaron en favor del gobierno por la crítica situación militar que prevalecía en el Pacífico y en la Costa del Pacífico en el verano de 1842, cuando se emitió la resolución. No se pronunciaron entonces sobre el problema más complicado del confinamiento. En buena medida debido a que esperaban que las autoridades militares cancelaran el programa de confinamiento y antes de que el juez A quo resolviera el caso de Korematsu, en el que sí se había impugnado como inconstitucional el acto de concentración forzosa.

En Korematsu, dos años más tarde, la Suprema Corte resolvió constitucional el confinamiento de ciudadanos de los Estados Unidos de origen japonés. No se trató de una decisión unánime como en Hirabayashi. En Korematsu vs. United States la Suprema Corte, con la ponencia del juez Hugo Black, declaró que los juicios de las autoridades militares deben verse bajo la perspectiva de que "la necesidad de acción era grande, mientras que el tiempo disponible era corto". Los actos militares no resultaban irracionales frente a la grave amenaza que representaba Japón y a la creencia razonable de que había japoneses-americanos que eran leales a Japón. ${ }^{16}$ Los disidentes en esta causa salvaron su responsabilidad histórica ante un asunto que ha sido señalado como un estigma de la Suprema Corte, al anteponer razones la violación de derechos elementales de los ciudadanos que sólo podrían vulnerarse en un estado de emergencia que nunca se declaró formalmente.

Los jueces Owen J. Roberts, Frank Murphy y Robert Jackson votaron en contra de la resolución mayoritaria. Roberts que había formado parte de una comisión que analizó el ataque a Pearl Harbor sabía que no

15 Hudson, David L., Jr., The Handy Supreme Court Answer Book, Detroit, Visible Ink Press, 2008, p. 252.

16 Ibidem, p. 253. 
existía evidencia de sabotaje en la Costa del Pacífico y señaló que había una evidente y clara violación de la Constitución. En su voto disidente Roberts expresó que si se condenaba a un ciudadano por no comparecer a un campo de concentración exclusivamente por razón de su origen, sin que exista evidencia de su falta de lealtad y buena disposición hacia los Estados Unidos y si esos son los datos que existen en el expediente, no es muy difícil llegar a la conclusión de que sus derechos constitucionales han sido violados. Murphy que había cuestionado la decisión de Hirabayashi, aunque votó con la mayoría en cuanto a la determinación del toque de queda, expresó que había caído en el "horrible abismo del racismo". Para Murphy se trató de una de los casos de privación de derechos constitucionales más completa en la historia de esa nación, en ausencia de la ley marcial. Jackson indicó por su parte en su voto disidente que la mayoría del órgano jurisdiccional había validado principios de discriminación racial en los procesos penales y los había trasplantado a los ciudadanos americanos. Señaló que si un militar viola los límites de la constitucionalidad se estaría en presencia de un incidente, pero si nosotros revisamos y aprobamos tal violación y traspaso de los límites constitucionales de tal incidente, eso se convierte en la doctrina constitucional. Nada ilustra mejor el peligro que lo que ha hecho la Suprema Corte con su resolución en este caso. ${ }^{17}$

La decisión de mantener a los japoneses recluidos mucho tiempo después de que pudieran representar una amenaza para la seguridad de la Costa Oeste y las decisiones de la Suprema Corte fueron un triunfo de la política sobre la ley. Dillon Meyer el Secretario del Interior, dependencia del Ejecutivo Federal que tenía a su cargo la administración de los campos de concentración para los japoneses-americanos, escribió una comunicación al secretario de la Defensa Walter J. McCloy (octubre de 1943), solicitando el regreso de los evacuados a la Costa Oeste en razón de que la necesidad militar para excluirlos de esa área había desaparecido. No obstante el Secretario de la Defensa le respondió que grupos poderosos y activos de California se oponían al regreso de los japoneses-americanos. El abogado general Francios Biddle acudió directamente al presidente Franklin D. Roosevelt más adelante (diciembre de 1943). En su comunicación señalaba que la práctica presente de mantener a leales ciudadanos de los Estados Unidos en campos de

17 Ibidem, p. 254. 
concentración sobre la base de su raza por un plazo mayor del absolutamente necesario, era peligroso y repugnaba a los principios del gobierno. Roosevelt ignoró la comunicación. Irons considera que la razón para este desdén del gobierno se explica por la proximidad de las elecciones de 1944 con las que Roosevelt fue electo por cuarta ocasión y los demócratas obtuvieron cuatro escaños de la Cámara en California. ${ }^{18}$

Independientemente de las supuestas razones políticas es paradójico que los Estados Unidos combatieran el racismo del III Reich y del imperio japonés durante la Segunda Guerra Mundial con una fuerza área, ejército y armada naval segregada racialmente por una parte y por la otra hubieran establecido campos de concentración para ciudadanos de su país en razón de sus características raciales y su origen familiar. ${ }^{19} \mathrm{El}$ presidente Harry S. Truman una vez concluida la Segunda Guerra Mundial ordenó la terminación de la segregación racial en las fuerzas armadas de los Estados Unidos. Tuvieron que pasar más de cuarenta años para que el Congreso de los Estados Unidos pidiera perdón oficialmente y entregara una compensación económica a los sobrevivientes de los campos de concentración. ${ }^{20}$

\section{LA MIGRACIÓN MEXICANA AL NORTE}

No ha sido mejor el trato que los nativistas dan a los mexicanos que emigran a los Estados Unidos. Escribe Carlos Fuentes que además de la historia de los que llegaron por el Atlántico de Europa pasando a un lado de la Estatua de la Libertad en la Bahía de Nueva York, en que se lee la inscripción : "vengan las masas que ansían la libertad... vengan los que no tienen techo.. levanto mi lámpara en esta dorada puerta", y de quienes arribaron de Asia por los puertos del Pacífico, hay otra historia de Norteamérica y la protagonizan los hispanoparlantes, la gran mayoría mexicanos. ${ }^{21}$ Quienes ya vivían en esas tierras desde la colonia, quienes

18 Irons, Peter, op. cit., p. 358.

19 El presidente Harry S. Truman, al final de la Guerra expidió una orden ejecutiva, en su carácter de Comandante en Jefe, prohibiendo la segregación racial en las fuerzas armadas.

20 Friedman, Lawrence M., op. cit., p. 526.

${ }^{21}$ Fuentes, Carlos, "La dorada lámpara de la migración", Reforma, 12 de julio de 2010 
fueron ciudadanos de la República Mexicana y quienes llegaron - siguen llegando - más tarde en distintas olas. La migración mexicana se inició propiamente en la época porfiriana. Desde entonces ha sido el tema central de la agenda de las relaciones entre los dos países. Los mexicanos llegaron a Estados Unidos impulsados por las difíciles condiciones del campo mexicano. Si bien su trabajo, eficaz, barato y disponible, era y es necesario en la agricultura. La expansión económica de los Estados Unidos atrajo la mano de obra mexicana en la minería y en la industria de la construcción. La situación de los mexicanos y su incorporación al sistema estadounidense fue distinta a la de los migrantes europeos. Sus condiciones de vida son precarias y son sujetos a tratos discriminatorios. El racismo actúa en contra de los mexicanos en Estados Unidos.

La Constitución de los Estados Unidos, en el artículo I, sección 8 establece la facultad del Congreso de legislar sobre naturalización. El primer esfuerzo por controlar la migración y regular los procesos de naturalización se dio con la Ley de Naturalización de 1790. El Congreso fijó entonces que para obtener la ciudadanía estadounidense se requerían dos años de residencia. El 1795, el requerimiento se incrementó a cinco años. En 1798, se expidieron las Leyes de Extranjeros y de Sedición. Se trataba de la protección que el Congreso deseaba brindar primero a la inminente amenaza de guerra con Francia y después a la llegada de migrantes que se sumarían a las filas del Partido Republicano liderado por Thomas Jefferson. Se penalizaron las críticas al gobierno federal de los Estados Unidos. Se incrementó el requisito de residencia para obtener la ciudadanía de cinco a catorce años. Aparte de estos intentos, el gobierno no hizo nada por limitar la migración hasta 1875, cuando se promulgó la primera ley de migración que restringía la entrada de extranjeros a los Estados Unidos. Esta ley prohibía el ingreso a los Estados Unidos de esclavos, prostitutas y "siervos" chinos. Otras leyes han modificado las condiciones de género, raza y edad para otorgar la ciudadanía.

En 1996, el Congreso de los Estados Unidos mediante reformas a las leyes migratorias confirió facultades discrecionales a los funcionarios de migración para deportar extranjeros. De esta manera si un oficial de migración estima que un extranjero cometió fraude o no tiene documentos válidos puede deportarlo, sin juicio previo. El sentido de otorgar estas facultades discrecionales tan amplias se encuentra en el criterio jurídico de que el acto de deportación no constituye una violación a derechos. No 
obstante la Suprema Corte ha intervenido para dar cauce jurídico a estos procedimientos y para evitar arbitrariedades de las autoridades que violen derechos humanos.

Los críticos de la función de la Suprema Corte se han opuesto a los criterios de ésta cuando han considerado que los extranjeros, aún los considerados como "ilegales" son "personas" como lo definen las enmiendas quinta y decimocuarta y además de que su estatus no se distingue del de los ciudadanos. El punto - señalan - es que mientras la Constitución le dio al Congreso la exclusiva facultad de determinar el número de migrantes que pueden ingresar al país, de qué manera los inmigrantes se convierten en ciudadanos de los Estados Unidos y si esos extranjeros tienen derecho a los mismos beneficios que otorga la ciudadanía estadounidense. ${ }^{22}$

Con fundamento en las cláusulas del debido proceso y de protección igualitaria de las leyes de la quinta y décima cuarta enmiendas constitucionales, de hecho y de derecho la Suprema Corte ha modificado las leyes migratorias. En algunos casos a través de sus resoluciones ha otorgado a no ciudadanos acceso igualitario a beneficios sociales. Así aconteció en la resolución de Graham vs. Richardson en la que la Corte estableció que algunas disposiciones de la legislación de Arizona que limitan los beneficios sociales a ciudadanos o residentes de los Estados Unidos que no cumplían con determinados años de residencia resultaban violatorios de la Cláusula de Protección Igualitaria ante la ley contenida en la Constitución. ${ }^{23}$ En los años sesenta los estados de Pensilvania y Arizona exigían que los extranjeros residentes permanentes deberían cumplir con requisitos mínimos para tener derecho a beneficios del sistema de seguridad social. Arizona por ejemplo exigía que los residentes que desearan beneficios deberían haber residido en el estado cuando menos quince años.

En 1969, Carmen Richardson, una mexicana de sesenta y cuatro años de edad que había emigrado al estado de Arizona de manera legal, después de residir trece años en ese estado, sufrió una incapacidad física. Solicitó las prestaciones de seguridad social, mismas que le fueron negadas por no cumplir con el requisito de residencia mínima de quince años.

22 Greenburg, Jan Crawford, Supreme Conflict, The Inside Story of the Struggle for Control of the United States Supreme Court, Nueva York, Penguin Books, 2008, p. 107.

23403 US 365 (1971), discutido el 22 de marzo de 1971, resuelto por unanimidad de nueve votos el 14 de junio de 1972. 
Richardson demandó al estado de Arizona y el juez de distrito falló en su favor. Su argumento se basó en el contenido de la decimocuarta enmienda constitucional relativa a la protección igualitaria de las leyes y su derecho constitucional al libre tránsito. Su caso, con otros de Arizona y Pensilvania, llegó a la Suprema Corte. El juez asociado Harry Blackmun señaló que los límites impuestos al gasto público por parte de los estados, en perjuicio de los extranjeros, resultaban inapropiados y poco razonables. Los extranjeros — señaló Blackmun - pagan impuestos, son llamados al servicio de las armas, viven años en los estados y contribuyen al crecimiento económico del estado por lo que no puede aducirse un interés público en especial al negarles beneficios en tanto los extranjeros también contribuyen fiscalmente. De esta manera, una ley que niegue beneficios de seguridad social y bienestar a los residentes extranjeros y otra que niegue tales beneficios a extranjeros que no han vivido en los Estados Unidos por un número determinado de años, viola la Cláusula de Protección Igualitaria de la ley.

Si bien la Suprema Corte, en términos generales, ha sostenido la facultad del Congreso sobre cuestiones de extranjería, el caso de Richardson y otros, son excepciones que limitan esa facultad federal. En otro asunto, la Suprema Corte señaló que era inconstitucional exigir requisitos de ciudadanía para desempeñar un trabajo en el gobierno. En 1970, cinco extranjeros residentes, empleados del servicio postal, y de otras oficinas gubernamentales tales como el Departamento de Salud, Educación y Bienestar fueron despedidos de sus cargos al descubrirse que no eran ciudadanos de los Estados Unidos, como lo establecen las reglas de la Comisión del Servicio Civil. Los cinco demandaron a la Comisión ante un tribunal federal. En 1976, en forma unánime, la Suprema Corte resolvió en el caso Hampton vs. Mow Sun Wong. Estableció que los requisitos de ciudadanía violaban las cláusulas del debido proceso y de la protección igualitaria de las leyes, así como del derecho de los extranjeros legales a la libertad.

En este asunto, el juez John Paul Stevens, quien a unos días de cumplir noventa años anunció su retiro que surtió efecto cuando se confirmó a Elena Kagan como su sucesora, rechazó el criterio de que las facultades del gobierno federal sobre extranjeros son absolutas. Por dar un ejemplo señaló que los extranjeros tienen derecho al debido proceso en las 
audiencias sobre deportación. ${ }^{24}$ John Paul Stevens expresó que la aplicación de las reglas por parte de la Comisión tienen un impacto sobre un grupo de personas (los extranjeros) sujetas a desventajas que no le son aplicables a las demás personas. "Los extranjeros no tienen derecho a voto, y se encuentran incapacitados por falta de conocimiento de nuestra lengua y nuestras costumbres". Las desventajas adheridas al aplicarse las reglas, como es la ilegibilidad para empleo en un sector mayor de la economía es de tal manera significativa que constituye una afectación de sus libertades. Por tal razón tal afectación debe darse bajo reglas del debido proceso. ${ }^{25}$ En este asunto estuvo con la mayoría en una decisión 5-4. No obstante, Stevens será recordado por su célebre declaración sobre el litigio electoral entre Bush y Gore. ${ }^{26}$

Los casos en que la Suprema Corte ha tratado cuestiones de nacionalidad, migración y derechos de los extranjeros, residentes legales o ilegales es muy amplia. Otra causa en que la Corte ha sido duramente criticada por su activismo judicial es el de Plyer vs. Doe. En 1975, el sistema escolar de Texas promulgó una ley para evitar la inscripción escolar de niños que sin haber sido admitidos legalmente en los Estados Unidos recibían educación en las escuelas públicas. Esta situación se daba principalmente en las ciudades que hacen frontera con México. La ley autorizaba a los distritos escolares a negar la inscripción a los niños mexicanos y a retener de los distritos escolares los fondos estatales destinados a la educación de estos estudiantes.

Se presentaron demandas en contra de la ley que llegaron a la Suprema Corte. Estos casos de consolidaron en el caso Plyer que fue resuelto por la mínima mayoría (5-4). William Brennan que escribió el proyecto, adoptado por la mayoría, señaló que el término "persona", contenido en la enmienda decimocuarta comprende también a los extranjeros ilegales, por la mera presencia de encontrarse físicamente en los Estados Unidos. Esto que parece ser algo natural al respeto que se deben los seres humanos, independientemente de su lugar de origen y de los documentos que

24 Hall, Kermit L., op. cit., p. 31.

25 Levin, Mark R., Men in Black, How the Supreme Court is destroying America, Washington D.C., Regnery Publishing Inc., 2006, p.109.

26 En Bush vs. Gore, Stevens que votó en contra de la mayoría (5-4) declaró que "si bien nunca se sabrá la identidad del ganador de esa elecciones presidenciales, una cosa quedó clara y es la identidad del perdedor: la confianza de la nación en el juez como el guardián imparcial del estado de derecho". 
acrediten o no su legal estancia en un determinado lugar, enfureció a muchos que lo consideraron un exceso. ${ }^{27}$

Brennan señaló que los niños no tenían responsabilidad alguna sobre su ingreso ilegal al país y por ello la legislación, al atribuir la responsabilidad y conducta inadecuada de sus padres a los niños no responde a los preceptos elementales de la justicia. Si bien la Suprema Corte reconoce que no existe un derecho constitucional a la educación pública, como el contenido en el artículo tercero constitucional de la Constitución de México, Brennan considera que la educación no es uno más de los beneficios que no se pueda diferenciar de las otras formas de bienestar social que contienen las leyes. Tanto la importancia de la educación - expresó en su ponencia - para el mantenimiento de nuestras instituciones básicas y el perdurable impacto de su ausencia en la vida de un niño son lo que hacen la distinción.

El pueblo americano siempre ha considerado a la educación y la adquisición del conocimiento como asuntos de la mayor importancia. Reconocemos a las escuelas públicas como una las instituciones vitales para la preservación del sistema democrático de gobierno. Y estas percepciones históricas de las escuelas públicas como las que incluyan los valores fundamentales necesarios para mantener un sistema político democrático ha sido confirmado por las observaciones de los científicos sociales. ${ }^{28}$

Brennan consideró que, el costo fiscal para las comunidades no era lo suficientemente alto como para justificar la privación de la educación pública a los inmigrantes ilegales. A pesar de esta posición que ejemplifica valores humanos y solidaridad internacional, hubo otras voces disidentes de esta propuesta. El conservador Chief Justice Warren Burger, emitió la opinión minoritaria a la que se sumaron Byron White y William Rehnquist, nominado por el presidente Nixon como juez asociado y quien después sería elevado a Chief Justice por el presidente Reagan. Para ellos la Suprema Corte actúa en lugar del Congreso, cuya falta de liderazgo efectivo es evidente al no atender los serios problemas que ha causado el flujo de millones de extranjeros ilegales a través de sus fronteras. Desde entonces se hablaba ya en un documento judicial del "fracaso en aplicar las leyes sobre migración por más de una década y la dificultad inherente

27 Levin, Mark R., op. cit., p. 111.

28 Plyler vs. Doe, 457 U.S. 202 (1982). 
y gastos de sellar nuestra vasta frontera, lo que ha creado un grave dilema socioeconómico". Es un dilema, dice el voto disidente, que no sólo no se ha resuelto completamente, sino que ni siquiera se ha abordado. Sin embargo, los jueces asociados consideraron que no es la función del Poder Judicial proveer un liderazgo efectivo, simplemente en razón de que las ramas políticas del gobierno han fallado al hacerlo.

\section{LA LEY DE ARIZONA SB 1070 Y LA FUNCIÓN DE LA SUPREMA CORTE}

El propósito de la Ley SB 1070 es que las dependencias estatales y municipales del estado de Arizona apoyen la aplicación de las leyes migratorias de carácter federal. Está explícita la intención de promover la cooperación estatal y municipal con las autoridades federales en materia migratoria, pero el objeto evidente es evitar la entrada y la estancia de extranjeros ilegales en Arizona. De tal manera establece que si un funcionario estatal o municipal tiene una duda razonable de la presencia de un extranjero ilegal su obligación es ponerlo a disposición de las autoridades federales. Aun sin una orden de detención, los funcionarios de Arizona pueden arrestar a un extranjero si considera que ha cometido una falta y por ello debe ser deportado. La Ley también promueve el intercambio de información sobre la condición de los extranjeros entre autoridades de todos los niveles. De esta manera no puede prohibirse o evitarse el intercambio y la apertura de la información para determinar la ilegitimidad de beneficios públicos, verificar domicilios o confirmar identidades. Otro elemento que generó polémica es la posibilidad jurídica de demandar judicialmente al funcionario que no aplique las leyes migratorias. Si se producen estas demandas los tribunales están obligados por ley a ordenar que se paguen a los denunciantes las costas judiciales y los gastos de abogados. Se establecerían penas civiles de no menos de mil dólares y no más de cinco mil dólares diarios. La presencia de un extranjero ilegal en Arizona, sea en un sitio público o privado, se castiga con penas de quinientos dólares y hasta mil si hay reincidencia. La presencia de un extranjero ilegal en territorio de Arizona sería equiparable al allanamiento (trespassing). El punto más vulnerable constitucionalmente es la duda razonable de quien puede ser considerado como ilegal, pues contiene un elemento racista. El otro dato es que el estado de Arizona incursionó con 
esta ley en un terreno que es de resorte federal. La ley pretende criminalizar la migración al facultar a la policía a detener a quien sea sospechosamente ilegal. Se ha cuestionado este ordenamiento por ser racista. La población total de Arizona es de 6.5 millones de habitantes, de los cuales 30 por ciento son mexicanos, es decir uno de cada tres. ${ }^{29}$ Se estima que el 8 por ciento de la población en Arizona es indocumentado.

La pregunta que debe hacerse es si corresponde a la Suprema Corte fijar políticas públicas o simplemente decir el derecho. Éste es el gran dilema entre quienes consideran que el papel de la Corte es meramente instrumental como la instancia que dice la ley, y quienes piensan que su papel debe ser activo, en favor de las causas políticas, económicas y sociales. Técnicamente la Suprema Corte de los Estados Unidos únicamente declara el derecho. No obstante se trata de un dilema no resuelto aun, pues es evidente que la Suprema Corte establece un diálogo entre sus decisiones y lo que el público estima deberían contener tales resoluciones. La juez asociada Sandra Day O'Connor, al referirse al efecto social y político que generó la decisión de la Corte de considerar como inconstitucionales las limitaciones impuestas por los estados a los abortos en los primeros tres meses del embarazo, estima que una nación que acepta dócilmente cada una de las decisiones de la Corte como infalibles e inmutables, hubiera decepcionado a los fundadores. ${ }^{30}$ La pregunta sobre el papel de la Corte en asuntos que impactan a la sociedad, habrá de ocupar nuevamente espacios en la opinión pública. Las resoluciones del Poder Judicial Federal derivadas de la expedición de la Ley SB1070, promulgada por el gobierno de Arizona, impugnada por el gobierno del presidente Barack Obama, pondrán a la Suprema Corte en el centro de la atención nacional e internacional.

El Congreso de Arizona preparó esta ley que pretende limitar la migración indocumentada al estado y facultar a las autoridades estatales y locales en materia migratoria. La gobernadora Jan Brewer recibió fuerte presión de distintos grupos, incluido el gobierno federal, así como organizaciones estatales, nacionales e internacionales para no promulgar la ley, que finalmente resistió. A pesar de todas las presiones incluida la del

29 Se daría el supuesto absurdo que uno de cada tres policías sería sospechoso de ser ilegal y tendría que auto detenerse.

30 O'Connor, Sandra Day, "The Majesty of the Law", Reflections of a Supreme Court Justice, Joyce, Craig, Nueva York, Random House, p. 45. 
propio presidente Obama finalmente promulgó la Ley SB 1070. Aun antes de que la gobernadora firmara el Decreto, el presidente Obama criticó la disposición duramente. En una ceremonia de naturalización hizo un llamado a los líderes del Congreso para hacer una revisión de las leyes migratorias y evitar la "irresponsabilidad de otros". En una clara alusión a la gobernadora dejó asentado el criterio de su gobierno sobre el contenido de la legislación.

El mismo día de su promulgación la gobernadora emitió una orden ejecutiva dirigida a las autoridades policíacas a fin de normar ciertos criterios en la aplicación de la ley. La gobernadora señaló que el texto de la ley es inoperante si los oficiales de la policía no están debidamente entrenados respecto de las normas contenidas en la Ley SB 1070, incluyendo las disposiciones sobre derechos humanos.

La orden ejecutiva enfatiza que para la aplicación de la ley no deberán tomarse en consideración cuestiones raciales. Los indicadores para considerar que alguien resulta sospechoso por existir una duda razonable de que se trate de un migrante ilegal, no deben ser raciales. El entrenamiento para evitar que esto suceda ha llevado a los oficiales de policía a un entrenamiento exhaustivo y forzoso. La dependencia del gobierno encargada de esta tarea es la Arizona Peace Officer Standars and Training Board (AZPOST) que circuló 15,000 instructivos. ${ }^{31}$

Algunas de las guías para determinar si se está en presencia de un inmigrante ilegal es si utilizan manga larga o varias prendas cuando hace calor, si trae consigo bolsas pequeñas en las que lleven ropa o artículos básicos, si evitan establecer contacto visual, si se muestran nerviosos, si transitan hacinados en vehículos viejos y descuidados, si se encuentran en los lugares tradicionales que utilizan los trabajadores migrantes para ofrecer sus servicios, o si no pueden proporcionar un domicilio permanente. Si estos datos se juntan con otros como que hablen un inglés deficiente, entonces puede estimarse que hay una duda razonable y proceder a las detenciones. Algo así como: persigan a los mexicanos, pero no lo hagan porque parezcan mexicanos". Justamente fueron estos elementos contenidos en los instructivos los que motivaron las demandas contra la Ley intentadas por distintas agrupaciones, incluidos los propios policías encargados de aplicar la ley y por organizaciones defensoras de derechos 
de los migrantes, a las que se sumó México, como amigo de la Corte (amicus curiae).

México participa en una de las demandas intentadas por diversas agrupaciones. Acompaña a ciudades, asociaciones y grupos de los Estados Unidos. ${ }^{32}$ Lo hizo en la causa Friendly House et al. vs. Michael B. Whiting. En esta causa participan como actores en la demanda organizaciones civiles como el Mexican American Legal Defense and Educational Fund, National Inmigration Law Center y la American Civil Liberties Union. México, según el comunicado de la Secretaría de Relaciones Exteriores, solicitó a la Corte Federal que se declare la inconstitucionalidad de la ley SB 070 y se impida su entrada en vigor. Según el propio comunicado "México tiene el deber de proteger a sus nacionales y asegura que el origen étnico no sea utilizado como criterio para cometer actos discriminatorios." La estrategia fue más allá al convocar a otras naciones

32 Estas agrupaciones participan en el juicio como amica curiae: Legal Momentum , National Council of La Raza, American Immigration Lawyers Association , International Longshore and Warehouse Union, Hispanic National Bar Association, Los Abogados Hispanic Bar Association of Arizona, United States Hispanic Chambe of Commerce, Lawyers' Committee for Civil Rights Under Law, Baltimore, City of, Berkeley, City of, Los Angeles, City of, Minneapolis, City of, Monterey, County of, New Haven, City of, Palo Alto, City of, Portland, City of, Saint Paul, City of, San Francisco, City of, San Francisco, County of, San Jose, City of, Seattle, City of, Arizona Attorneys for Criminal Justice, Asian American Institute, Anti-Defamation League, United Mexican States, AmericanArab Anti-Discrimination Committee, Arab Community Center for Economic and Social Services, Asian American Legal Defense Fund, Center for Community Change, Coalition for Humane Immigrant Rights of Los Angeles, Equal Justice Society, Hebrew Immigrant Aid Society, Immigration Equality, Mexican American Bar Association of Texas, National Asian Pacific American Bar Association, National Black Law Students Association, National Center for Lesbian Rights, National Immigration Project of the National Lawyers Guild, National Korean American Service and Education Consortium, National Organization for Mexican American Rights, OneAmerica, Organization of Chinese Americans, Public Counsel, Society of American Law Teachers, Southern Center for Human Rights, Arab American Institute, Arizona Asian-American Bar Association, Arizona Opportunities Industrialization Center, Asian Law Caucus, BPSOS Incorporated, Clergy \& Laity United for Economic Justice, Greater Phoenix Urban League, Hispanic Bar Association of New Jersey, Illinois Coalition for Immigrant and Refugee Rights, Lambda Legal Defense and Education Fund Incorporated, Lawyers' Committee for Civil Rights of the San Francisco Bay Area, League of Woman Voters of Arizona, League of Woman Voters of the United States, Muslim Advocates, Muslim Public Affairs Counsel, New York Immigrant Coalition, Progressive Jewish Alliance, Sikh American Legal Defense and Education Fund, American Bar Association and American Unity Legal Defense Fund, Inc. 
latinoamericanas para que participarán con México como "Amigos de la Corte" en este proceso. ${ }^{33}$ No es la primera ocasión que México acude a tribunales extranjeros como amicus curiae. Lo hizo en el asunto de Humberto Álvarez Machain. ${ }^{34}$

La participación formal de México como amicus curiae en el juzgado federal que revisa la constitucionalidad de la Ley de Arizona, independientemente de las razones políticas y humanitarias es un error jurídico. Al haberse aceptado la intervención de México como amicus curiae se violó la Constitución mexicana. Conforme al texto, entre las obligaciones constitucionales del presidente está seguir los principios de la política exterior mexicana entre los cuales está la no intervención. La participación de México en un litigio sobre la constitucionalidad de una ley de un país extranjero es una intervención prohibida por la Constitución mexicana. Por otra parte México quedó sometido a la jurisdicción federal de los Estados Unidos. La juez de distrito Susan Bolton, encargada de la causa, indicó por ejemplo, que la promoción presentada por México era demasiado abultada y tenían que reducirla a 10 páginas, lo que los representantes del gobierno de México - abogados estadounidenses contratados por la Cancillería - hicieron diligentemente. Llegó a decir que era de tal manera abundante la documentación recibida que ponía en entredicho la capacidad del tribunal para atender las demandas. La juez Bolton recibió además muchas críticas por haber aceptado la intervención de México, lo que podría generar hasta una apelación, pues no es claro el interés jurídico de México en un asunto de constitucionalidad de un país extranjero. ${ }^{35}$

Se presentaron diversas impugnaciones a la ley. Una de ellas es de David Salgado, policía de la ciudad de Phoenix, quien también acudió al tribunal federal para señalar que la ley violaba sus derechos, al entrar en vigor, cuando tenga que preguntar a aquellos que detenga sobre su situación migratoria cuando exista "duda razonable" que se encuentra ilegalmente en el país. De igual manera señala en su demanda el riesgo que corre de ser demandado si no cumple estrictamente con su función de

33 Guatemala se sumó a la promoción de México por medio de la Embajada de México en Washington, La Prensa.hn_internacionales, 13 de julio de 2010.

34 Gómez Robledo Alonso, Extradición en derecho internacional, México, UNAM, Instituto de Investigaciones Jurídicas, 2000, pp. 29-44.

35 Una discusión más detallada en Melgar, Mario, “¿Amigos de la Corte?”, Excélsior, 6 de julio de 2010 . 
vigilante migratorio, como lo prevé la ley, si es que no aplica la ley con toda la extensión que permite la ley migratoria federal.

Como en cualquier litigio en que hay dos partes enfrentadas, la gobernadora y los legisladores de Arizona no están solos. Mike Coz, el abogado general del estado de Michigan y quien aspira a gobernar ese estado norteño, apoyó a Arizona en las demandas. Lo siguieron los estados de Alabama, Florida, Nebraska, Pensilvania, Carolina del Sur, Sur Dakota, Texas, Virginia y las Islas Marianas del Norte. El argumento que utilizaron, en su respaldo a la Ley de Arizona, es que el gobierno federal no ha hecho nada en materia migratoria por lo que corresponde a los estados ejercer esa facultad. La promoción fue presentada el último día que lo permiten las reglas procesales. La promoción señala que "por medio de una demanda y no de procesos legislativos el gobierno federal pretende negar las facultades preexistentes de los estados para verificar la calidad migratoria y de igual manera pretende evitar el auxilio que los estados pueden legalmente brindar al gobierno federal".

El contenido central de la ley es evitar la migración de ilegales y para ello contiene disposiciones a fin de que los inmigrantes deban llevar consigo la documentación que acredite su estatus migratorio. Como había señalado anteriormente, la parte más vulnerable de la ley es que faculta a la policía a preguntar a cualquier que parezca "sospechoso" sobre sus origen, sus papeles, su actividad, o cuando exista duda razonable de que su estancia en el país sea ilegal.

La ley ha polarizado el ambiente político alrededor del tema migratorio. La gobernadora ha contribuido a tal polarización con sus declaraciones. En una entrevista de prensa después de firmar la Ley le pidieron que por favor explicara el criterio que se utilizara para determinar si alguien es un inmigrante ilegal, ¿a quién se parece un inmigrante ilegal?, le preguntaron. Dijo que ella no sabe cómo es un inmigrante ilegal, pero que habría un programa que evitaría cualquier insinuación racial o persecución por estos motivos. El senador por Arizona Russel Pearce fue más directo al decir que noventa por ciento de los extranjeros ilegales provienen del sur (México mayoritariamente), así que "su apariencia será sin duda un factor".

La administración del presidente Obama interpuso una demanda en contra de la ley que será revisada por el poder judicial federal de los Estados Unidos y que presumiblemente llegará hasta la Suprema Cor- 
te de Justicia. ${ }^{36}$ Contrario a lo que pudiera pensarse, el argumento para impugnar la constitucionalidad de la Ley de Arizona no fue su evidente violación a la décima cuarta enmienda por su sentido racista, sino que la demanda incursionó por cuestiones técnicas sobre facultades del gobierno federal y de los estados sobre cuestiones migratorias. La opinión pública esperaba que la demanda del gobierno federal se sustentara en la décima cuarta enmienda que contiene la cláusula del debido proceso y la cláusula de protección igualitaria, no obstante se planteó con base en una cuestión técnica del federalismo como es la distribución de competencias que hace el texto constitucional y las interpretaciones que ha dado la Suprema Corte. La demanda se alejó de lo que se considera la parte más vulnerable de la ley como es la facultad a la policía para que persiga a quienes generen una duda razonable de que sean inmigrantes ilegales. Llama la atención la omisión sobre el contenido racista de la ley particularmente porque el abogado general de los Estados Unidos, Eric Holder hizo aquella famosa declaración de que "los Estados Unidos es una nación de cobardes en cuanto a raza se refiere".

Para Obama en el sistema constitucional de los Estados Unidos - dice su demanda - el gobierno federal tiene preeminente autoridad para reglamentar las cuestiones migratorias. Si bien los estados pueden afectar a los extranjeros, los estados no deben establecer su propia política migratoria o aplicar sus leyes, si éstas interfieren con las leyes federales. El juez federal y eventualmente la Suprema Corte de ese país resolverán si la Ley de Arizona vulnera la Constitución. El juicio tiene extrema importancia. Si se dejara en manos de los estados la política de control migratorio se generaría un caos nacional. En cuanto a la defensa de los derechos humanos habrá que esperar la decisión de la Suprema Corte la que fijará el criterio definitivo sobre la persecución, detención o arresto de quienes, como dice la ley, tengan un status migratorio sobre el que exista "duda razonable" de que es ilegal.

La Suprema Corte de Estados Unidos tiene una larga historia de respaldo a los derechos humanos que no se ve la razón para que cuando lleguen estos casos no fije criterios generales aplicables a todas las personas, así sean y parezcan mexicanos. No obstante que en las últimas décadas la Suprema Corte ha jugado un papel importante en establecer reglas

36 The United States of America vs. The State of Arizona; and Janice K. Brewer, Governor of the State in her Official Capacity. 
relacionadas con la forma en que los migrantes pueden acceder al país, permanecer en él, y hasta beneficiarse socialmente del sistema de seguridad social y bienestar que los Estados Unidos, bien el Congreso nacional o los estados han diseñado para sus ciudadanos, no siempre ha sido así. La resolución que eventualmente emita la Suprema Corte de los Estados Unidos sobre la constitucionalidad de la Ley de Arizona SB 1070, marcará una pauta en el complicado tráfago migratorio.

\section{CONCLUSIÓN}

El contenido de la Ley de Arizona SB1070 y de otras similares que, se anunció, expedirían diversos estados de la Unión Americana sobre el tema migratorio, serán motivo de controversias constitucionales que serán atendidas por los tribunales federales de los Estados Unidos. Las legislaturas de Oklahoma, Carolina del Sur, Idaho, Utah, Missouri, Texas, Carolina del Sur Maryland, Minnesota y Colorado han considerado la expedición eventual de leyes con contenidos similares a la de Arizona. Las resoluciones de los tribunales federales sobre la constitucionalidad de estas leyes sobre migración serán probablemente atendidas en última instancia por la Suprema Corte de los Estados Unidos.

La Suprema Corte de los Estados Unidos tiene una jurisdicción original como una derivada de apelaciones. La jurisdicción original de la Corte comprende las facultades en las controversias entre diferentes estados de la Unión, igualmente en aquellos casos en que un estado sea parte. La jurisdicción de apelación se refiere a la facultad que tiene un tribunal superior de revisar las resoluciones de uno inferior. Ocurre cuando una parte perdidosa acude a la Suprema Corte en apelación por la decisión que impugna. La Suprema Corte tiene facultades para revisar decisiones de los tribunales federales de apelación, decisiones de las supremas cortes de los estados que se refieran a una cuestión federal generalmente de constitucionalidad federal y a las decisiones de paneles especiales integrados por tres jueces federales de los tribunales federales de distrito La Suprema Corte tiene una jurisdicción discrecional, es decir ella misma determina que asuntos debe atender. La Suprema Corte selecciona anualmente alrededor de ochenta casos de nueve mil que se presentan. Conforme a las Reglas de la Suprema Corte, la Regla 10 establece algunas directrices, que no de derecho, pero si discrecionales que la Suprema 
Corte puede atender relacionadas con el writ of certiorari, si existen razones suficientemente especiales e importantes para hacerlo. ${ }^{37}$ La magnitud del tema migratorio y las repercusiones de todo orden sugieren que de plantearse la revisión ante la Suprema Corte, ésta habrá de avocarse a resolver el asunto.

Cuando la Suprema Corte declara una ley inconstitucional, su decisión solamente puede ser modificada por una decisión posterior de la propia Corte o por una enmienda constitucional. En la historia de la Suprema Corte siete de veintisiete enmiendas constitucionales han invalidado decisiones de la Suprema Corte. Sin embargo, la mayoría de los casos que atiende la Suprema Corte no se refieren a la constitucionalidad de las leyes, pero sí a la interpretación de leyes federales.

Las determinaciones de los casos que la Suprema Corte revisará es discrecional pero sujeta a procedimientos colegiados. Hay una lista que se discute entre los jueces asociados. En 2001, en la ciudad de Guanajuato, el Chief Justice William Rehnquist dio una conferencia en la que explicó el mecanismo para seleccionar los casos que la Suprema Corte atiende cada año. Rehnquist puso énfasis en las tres tareas más importantes de la Corte: (a) seleccionar los casos que habrán de decidirse, (b) decidir tales casos, lo que supone estudiar el expediente, escuchar los argumentos que se presentan en forma oral a cargo de los abogados y votar la resolución y (c) preparar por escrito las opiniones (votos) que sostienen y explican el resultado al que llegó la mayoría, así como los votos disidentes de los jueces asociados que no están de acuerdo con el razonamiento de la mayoría. ${ }^{38}$

Se requieren cuatro votos de los jueces asociados para que la Suprema Corte determine atender un asunto. Esta política no escrita de que al menos sean cuatro jueces asociados los que acepten resolver un asunto, fue determinada por la propia Corte. Decidieron que con cuatro votos, no cinco que representan la mayoría del cuerpo colegiado, de los nueve mil asuntos que se presentan se decida resolver alrededor de ochenta que habrán de integrar la agenda del Tribunal. El personal auxiliar de los jueces prepara memoranda que los jueces revisan para votar cuales asuntos son

3728 U.S.C.A, 1254, 1257: Sup.Ct. Rules 10.

38 Universidad de Guanajuato, 27 de septiembre de 2001, Conferencia del Chief Justice William Rehnquist. 
susceptibles de atención, si se reúnen los cuatro votos, entonces el asunto se enlistará para resolución del pleno.

Es previsible que uno de los casos que atienda la Suprema Corte en el futuro cercano sea el de la Ley de Arizona SB 1070. Su importancia política así lo determinará. La Suprema Corte tendrá que fijar reglas sobre las facultades del gobierno federal en materia migratoria para evitar que se generé un caos jurídico si prevalecen disposiciones estatales inconexas que podrían configurar un mosaico de decisiones sobre un asunto, como el migratorio, que exige uniformidad de enfoques y criterios.

Desde hace años México propuso a los Estados Unidos un acuerdo migratorio que ha variado en sus alcances. Inicialmente el gobierno del presidente Vicente Fox planteó un acuerdo migratorio que incluyera la legalización de los mexicanos indocumentados en los Estados Unidos, así como un programa de visas para quienes pretendieran emigrar. Se le imputa a los ataques terroristas del 11 de septiembre de 2001, la razón para el fracaso de esta propuesta. A partir de ese momento, no obstante que la diplomacia mexicana siguió insistiendo en el tema no se logró ninguna concesión. El tema dejó de ser bilateral para convertirse en un asunto de política interior de los Estados Unidos.

Se generaron varios proyectos de legislación sobre migración, señaladamente la Ley denominada "Secure America and Orderly Immigration Act" de 2005 comúnmente conocida como la Ley Migratoria Kennedy-McCain. Esta disposición gozó de un buen impulso inicial pero fue derrotada en los trámites legislativos. ${ }^{39}$ El senador por Arizona, John McCain que la apoyó a pesar de ser republicano, cambió de criterio y se sumó años más adelante, a los promotores de la Ley de Arizona. El proyecto de Ley Kennedy-McCain quedó olvidado y fue sustituido por la decisión de seguir la construcción de una barda que impida el paso de migrantes indocumentados a lo largo de la frontera de México con los Estados Unidos. El presidente Obama prometió en su campaña política una ley integral de migración que no ha avanzado por las difíciles condiciones de la economía global y particularmente de la de los Estados Unidos.

39 Los puntos centrales consistían en (1) Se permitiría el ingreso de 400,000 trabajadores migrantes a quienes se les darían visas por tres años; (2) Cerca de 10 millones de indocumentados tendrían que registrarse, pagar una multa de dos mil dólares y pasar en examen de inglés, podrían obtener la ciudadanía en seis años(3) se multaría a los empleadores que contraten indocumentados y (4) se asegurarían las fronteras. 
Ante este panorama de la imposibilidad de un acuerdo migratorio entre México y los Estados Unidos y las dificultades del Congreso estadounidense para legislar en materia migratoria integral, los criterios que eventualmente fije la Suprema Corte de los Estados Unidos resultarán cruciales. Si la Suprema Corte decide revisar en apelación la resoluciones de los tribunales federales sobre la constitucionalidad de la Ley de Arizona SB 1070, afectará el futuro de millones de migrantes que viven en las sombras en ese país y de otros millones de trabajadores migrantes que seguirán buscando en los Estados Unidos el trabajo y sustento para sus familias que no encuentran en sus países de origen. A lo largo de la historia constitucional de Estados Unidos la Suprema Corte ha tenido en sus manos los temas políticos, sociales y económicos más relevantes de ese país. El de migración es uno de ellos por las implicaciones internacionales, jurídicas, económicas políticas y morales que tienen consigo el trabajo de millones de personas y el respeto a sus derechos fundamentales como seres humanos. 